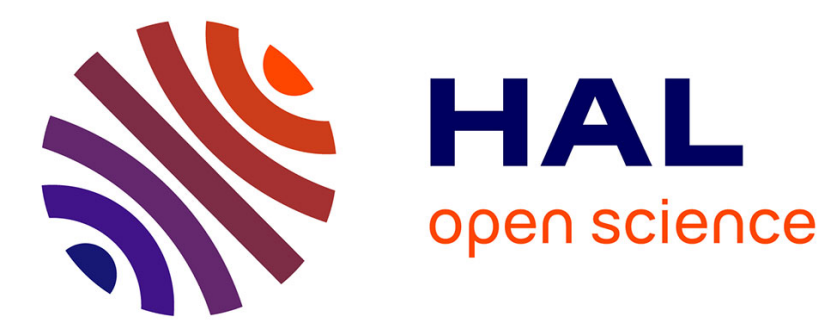

\title{
Condensation coefficients in plasma sputtering deposition
}

\author{
Pascal Brault, A.-L. Thomann, J.-P. Rozenbaum
}

\section{To cite this version:}

Pascal Brault, A.-L. Thomann, J.-P. Rozenbaum. Condensation coefficients in plasma sputtering deposition. Journal of Physics D: Applied Physics, 2007, 40, pp.2121-2123. 10.1088/0022-3727/40/7/039 . hal-00180178

\section{HAL Id: hal-00180178 https://hal.science/hal-00180178}

Submitted on 3 Oct 2008

HAL is a multi-disciplinary open access archive for the deposit and dissemination of scientific research documents, whether they are published or not. The documents may come from teaching and research institutions in France or abroad, or from public or private research centers.
L'archive ouverte pluridisciplinaire HAL, est destinée au dépôt et à la diffusion de documents scientifiques de niveau recherche, publiés ou non, émanant des établissements d'enseignement et de recherche français ou étrangers, des laboratoires publics ou privés. 


\title{
Condensation coefficients in plasma sputtering deposition
}

\author{
Pascal Brault $\S$, Anne-Lise Thomann, Jean-Philippe \\ Rozenbaum
}

Groupe de Recherches sur l'Energétique des Milieux Ionisés, UMR6606 CNRS-Université d'Orléans BP 6744, 45067 Orléans Cedex 2, France

\begin{abstract}
Optical Emission Spectroscopy and Rutherford Backscattering Spectrometry are combined to determine condensation coefficients for plasma sputtering deposition. The method is applied for palladium deposition onto various substrates and condensation coefficients are found to lie between 0.4 and 0.9 .
\end{abstract}

PACS numbers: 81.15.Cd, 52.77.Dq

Submitted to: J. Phys. D: Appl. Phys.

$\S$ Corresponding author: Fax +33(0)2 384171 54, e-mail: Pascal.Brault@univ-orleans.fr 
Measuring condensation coefficients remains a very difficult task in plasma sputtering deposition. The knowledge of both incoming specie fluxes and deposited amount or growth rates are required in non ideal conditions. Indeed the growing thin film is continuously subjected to ion bombardment and interactions with other energetic species as metastable atoms or molecules, electrons, photons. These species can thus modify the condensation coefficient as compared to vacuum deposition. Thus simple pictures emerging from the description of vacuum deposition can not hold in some situations. Many attempts have been tried, like quartz microbalance, which measures mass differences and thus gives the deposited quantity but alone, it is not sufficient for deducing condensation coefficients. For dielectrics materials or semiconductors ellipsometry can be used for such determination, but it is not appropriate for metals. More sophisticated techniques as laser induced fluorescence and laser or broad band absorption have also been used for evaluating condensation coefficients [1]. In this article we suggest another simple way for the determination of condensation coefficients by combining Optical Emission Spectroscopy (OES) to follow diffusion of depositing species and Rutherford Backscattering Spectrometry (RBS) to measure growth rates for plasma sputtering. The method could be extended to some other plasma deposition methods where the depositing species do not react in the gas phase.

The experimental setup dedicated to plasma sputtering deposition has been widely described elsewhere [2, 3, 4, 5] and is pictured on Fig. 1. Let us recall main features of interest for OES . A low pressure (1-100 mTorr) high frequency (100 MHz) plasma

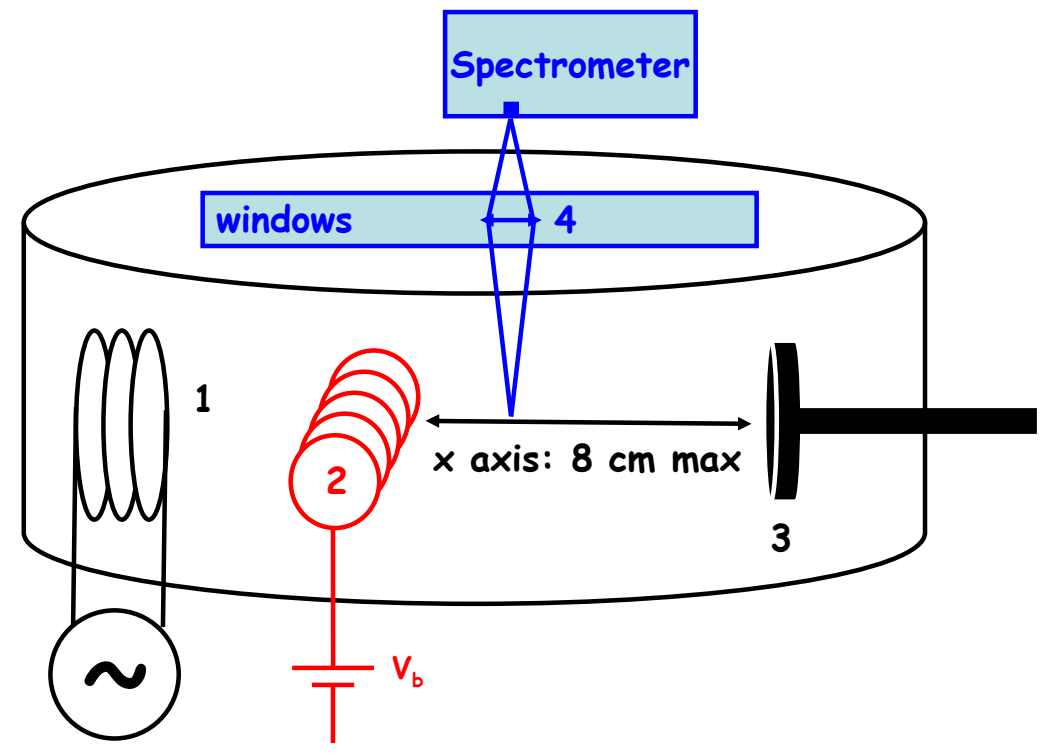

Figure 1. Schematic drawing of the sputtering reactor. 1-High Frequency Antenna creating the plasma, 2- Palladium biased target wire, 3-Grounded substrate, 4-Optical plasma light collection and recording

is created in argon gas with input power of several Watts. The features of this plasma 
are reported in Table 1 . The metal atom source (an helicoidal wire) is negatively biased

Table 1. Global properties of the sputter plasma [5]. P is the working argon pressure, $V_{p}$ the plasma potential, $V_{f}$ the floating potential, $n_{e}$ the electron density and $k T_{e}$ the electron temperature at sbstrate position

\begin{tabular}{ccccc}
\hline $\mathrm{P}(\mathrm{m}$ Torr $)$ & $\mathrm{V}_{p}(\mathrm{~V})$ & $V_{f}(\mathrm{~V})$ & $n_{e}\left(\mathrm{~cm}^{-3}\right)$ & $k T_{e}(\mathrm{eV})$ \\
\hline 100 & 100 & 90 & $5.10^{9}$ & 2 \\
\hline
\end{tabular}

$\left(V_{b}=0\right.$ to $\left.-350 \mathrm{~V}\right)$ so that the plasma ions gain sufficient energy to induce sputtering. Then sputtered atoms travel across the chamber (several $\mathrm{cm}$ ) and reach the substrate where growth starts. At the same time, the substrate is also exposed to the plasma, and thus submitted during deposition to a ion flux [2, 3]. The substrate temperature is not controlled but was measured to not increase above $310 \mathrm{~K}$. A quartz window is placed on the top of reactor, allowing to collect light emitted by excited $\mathrm{Ar}$ and sputtered atoms at various distances from the sputtering wire, with a spatial resolution around $1 \mathrm{~mm}$. Light is collected by an optical fiber connected to the entrance slit of a monochromator (SectraPro 275, Acton Research Corporation). The dispersed light is analysed by a water cooled $\left(-25^{\circ} \mathrm{C}\right)$ optical multichannel analyser (EG\&G $1453 \mathrm{CCD}$ array) linked to an interface control (EG\&G 1471). Data acquisition is monitored by a PC computer through the OMAvision software (EG\&G). Growth rates were measured by ex-situ Rutherford Backscattering Spectroscopy using a $2 \mathrm{MeV} \alpha$ particle beam extracted from a Van de Graaf accelerator.

The condensation coefficient $S(x)$ is defined as the ratio of the growth rate to the impinging atom flux :

$$
\tau(x)=S(x) \phi(x)
$$

where $\phi(x)$ is the impinging atom flux $\left(\mathrm{cm}^{-2} \mathrm{~s}^{-1}\right)$ and $\tau(x)$ is the growth rate $\left(\mathrm{cm}^{-2}\right.$ $\mathrm{s}^{-1}$ ) at the distance $x$ from the sputtering source. $\phi(x)$ can be evaluated using OES in the following way. First, recall that the intensity emitted by atoms excited by an electron impact with mass $m_{e}$, energy $E$, excitation cross-section $\sigma(E)$ and density $n_{e}(x)$, provided that $T_{e}$ (the electron temperature), and excited state lifetime are constant over the path length, is given by :

$$
I(x) \propto k_{e} n_{e}(x) N(x)
$$

where $k_{e}=\int_{0}^{\infty} \sigma(E) f(E)\left(\frac{2 E}{m_{e}}\right)^{\frac{1}{2}} d E$ is the excitation rate. $k_{e}$ is assumed here constant, because in our experiments, we observe that the $\operatorname{Ar}(750.4 \mathrm{~nm})$ emission line intensity is constant along substrate to target distance $x$. When it is not the case $k_{e}$ should depend upon distance $x$ and such dependence should be taken into account. $f(E)$ is the electron energy distribution function, $N(x)$ being the density of atoms in the fundamental state. Thus we have to correlate the intensity $I(x)$ with the atom flux $\phi(x)$ or the density in the fundamental state $N(x)$. It remains only to know the evolution of the electron density $n_{e}(x)$. If sputter or buffer gas is argon (this is usually the case), such evolution 
Table 2. Fitting laws of emission intensities $I_{P d}(x)$ and growth rates $\tau(x)$ at 100 mTorr.

\begin{tabular}{ccc}
\hline$V_{b}(\mathrm{~V})$ & $\tau(x)\left(10^{14} \mathrm{~cm}^{-2} s^{-1}\right)$ & $\mathrm{I}_{P d}^{363.47 n m}(x)$ (arb. units) \\
\hline-100 & $0.4 \frac{5}{x^{2}+5}$ & $106 \frac{5}{x^{2}+5}$ \\
-350 & $1.64 \frac{11}{x^{2.3}+11}$ & $289 \frac{11}{x^{2.3}+11}$ \\
\hline
\end{tabular}

can be determined by recording emission line proportional to $n_{e}(x)$ as the $750.4 \mathrm{~nm}$ line of the $1 \mathrm{~s}^{2}-2 \mathrm{p}^{1}$ transition. Indeed, the upper level of this transition is mainly populated by electron collisions from the fundamental level and thus if $T_{e}$ is constant, then the intensity of this $750.4 \mathrm{~nm}$ line becomes proportional to $n_{e}(x)$. It is also possible to follows $n_{e}(x)$ evolution from Langmuir probe measurements [4, 5, 6]. In that case, $n_{e}(x)$ is given by the Bohm criterion : $n_{e}(x)=\frac{j(x)}{0.6 q}\left(\frac{m_{i}}{k T_{e}}\right)^{\frac{1}{2}}$ [6] , where $j(x)$ is the measured saturation ion current, $m_{i}$ being the ion mass, $\mathrm{q}$ the elementary electron charge. $\tau(x)$ is measured by RBS on deposits at different distances from the sputtering source. Thus, we have $I(x) \propto N(x) n_{e}(x)$ and we have also, $\phi(x) \propto N(x)$, when $v(x)$, the velocity of incoming species is constant. Thus $\phi(x)=\alpha \frac{I(x)}{n_{e}(x)}$, where $\alpha$ is a constant and it follows that $\tau(x)=\alpha S(x) \frac{I(x)}{n_{e}(x)}$. Moreover $\phi(x=0)$ is the flux at the source and in the case of sputtering, it simply reads : $\phi(0)=\frac{i \gamma}{q A}$, where $i$ is the target (of area A) current and $\gamma$ the sputtering yield (which depends on $\mathrm{P}$ and $V_{b}$ ). So we can now recover the value of the constant $\alpha: \alpha=\frac{i \gamma n_{e}(0)}{q A I(0)}$ and thus, we find the following simple relation between the condensation coefficient $S(x)$ and the measured quantities $n_{e}(x), I(x)$ and $\tau(x)$ :

$$
S(x)=\frac{I(0)}{I(x)} \frac{n_{e}(x)}{n_{e}(0)} \frac{q A}{i \gamma} \tau(x)
$$

We have used these relations for evaluating the condensation coefficient of sputtered Pd onto $\mathrm{SiO}_{2} / \mathrm{Si}(100)$. In Figs. 2 and 3 are respectively plotted emission intensities of the $\mathrm{Pd} 363.47 \mathrm{~nm}$ line and the $\mathrm{Pd}$ growth rates as a fonction of the position in the reactor, for two bias potential values $V_{b}$. Both OES and RBS measurements display evolutions that can be expressed in the form : $h(x)=h(0) \frac{a}{a+x^{n}}$. In Table 2 are reported the fitting laws of the emission intensities (363.47 $\mathrm{nm}$ line of $\mathrm{Pd} \mathrm{I}$ ) and of growth rates (measured by RBS). Examination of Table 2 shows that $n=2$ or is closed to 2. The fact that $a$ and $n$ are identical for $\tau(x)$ and $I(x)$ in different conditions results only from the fitting which was not constrained. It means that the sputtered Pd atoms expand spherically in the plasma chamber. This is not surprising because collisions, along the diffusion path, with Ar gas, at 100 mTorr, are sufficient for averaging all the directions. We can also see in Table 2, that $\frac{\tau(x)}{I(x)}=$ constant $=\frac{\tau(0)}{I(0)}$. Also, in our 


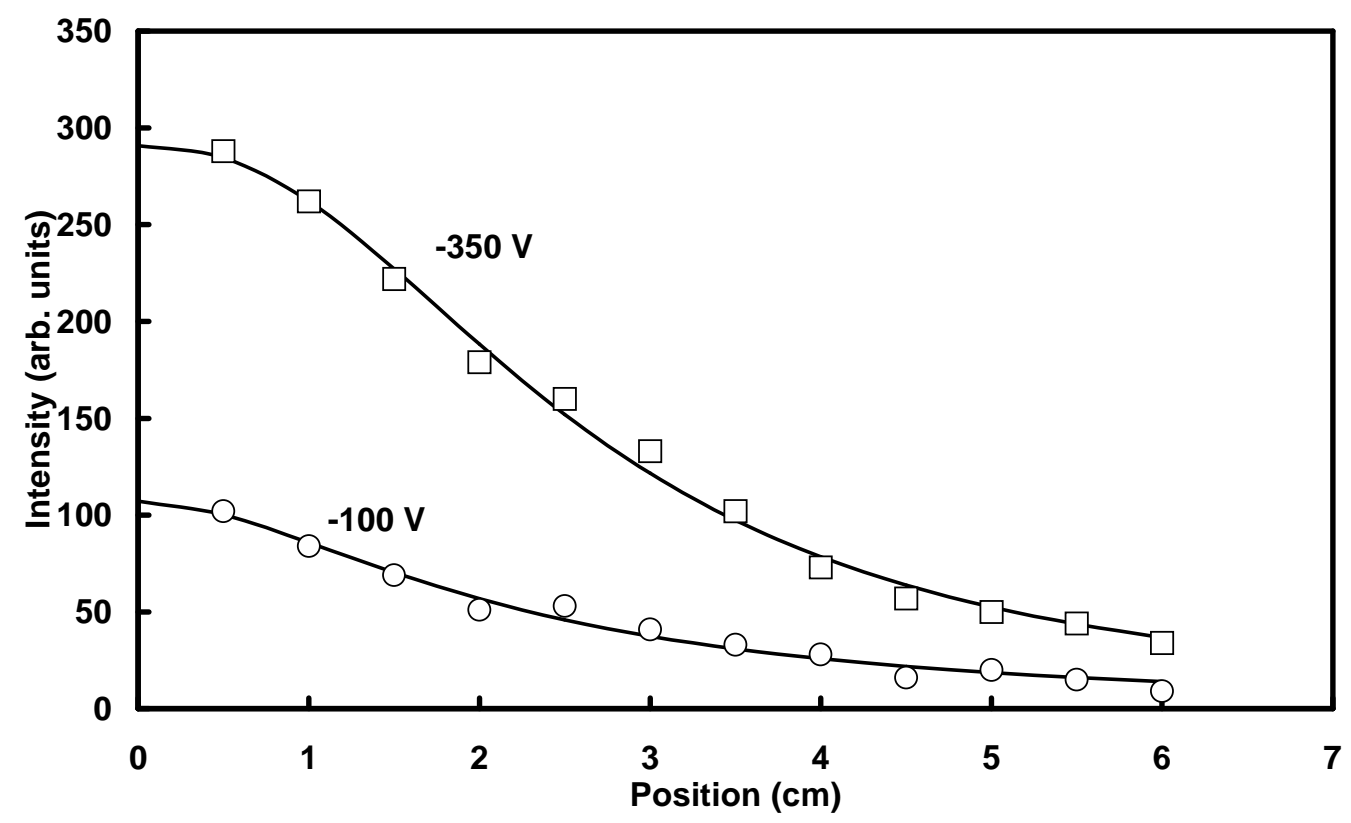

Figure 2. Evolution of the $363.47 \mathrm{~nm}$ line of Pd I along the diffusion path between $\mathrm{Pd}$ source $(\mathrm{x}=0 \mathrm{~cm})$ and the reactor wall. Pressure is $100 \mathrm{~m}$ Torr and bias potential is $V_{b}=-100 \mathrm{~V}$ (open circle) and $V_{b}=-350 \mathrm{~V}$ (open square). The solid lines are the best fits for the diffusion laws (see Table 2)

conditions ( $\mathrm{P}=100$ mTorr $)$, the electron density $n_{e}(x)$ is constant in the diffusion region [5] then $S(x)$ remains constant along the diffusion path and : $S=\frac{q A \tau(0)}{i \gamma}$. We find that the condensation coefficient, at $\mathrm{P}=100$ mTorr, depends on the target bias voltage $V_{b}$ (and then on pd flux) and takes the value $\mathrm{S}\left(\mathrm{Pd} / \mathrm{SiO}_{2} / \mathrm{Si}(100),-100 \mathrm{~V}\right) \approx 0.4$ and $\mathrm{S}\left(\mathrm{Pd} / \mathrm{SiO}_{2} / \mathrm{Si}(100),-350 \mathrm{~V}\right) \approx 0.85$. This can be explained by the fact that, at low $\mathrm{Pd}$ incoming flux (i.e. low $\mathrm{Pd}$ wire bias voltage), the ratio of Ar ion flux to $\mathrm{Pd}$ atoms flux is higher than with larger Pd flux. Thus statistically, deposited Pd atoms suffer more collisions with impinging $\mathrm{Ar}^{+}$ions, thus $\mathrm{Pd}$ desorption during deposition could be increased. So the effective condensation can be lowered. This would be consistent with previous experiments [3] where ions are observed also to increase the compacity of clusters. This could be achieved by desorbing less bound atoms at the periphery of the clusters. Let us examine the values of condensation coefficient on different subtrates. In Table 3 deposited quantities have been measured using RBS on different substrates at $\mathrm{P}=100 \mathrm{~m}$ Torr and $V_{b}=-100 \mathrm{~V}$ and the estimated condensation coefficient assuming that the deposited quantity ratio between different substrates are the same for condensation coefficient. These condensation coefficients have values close to reported values of $\mathrm{Pd}$ for 


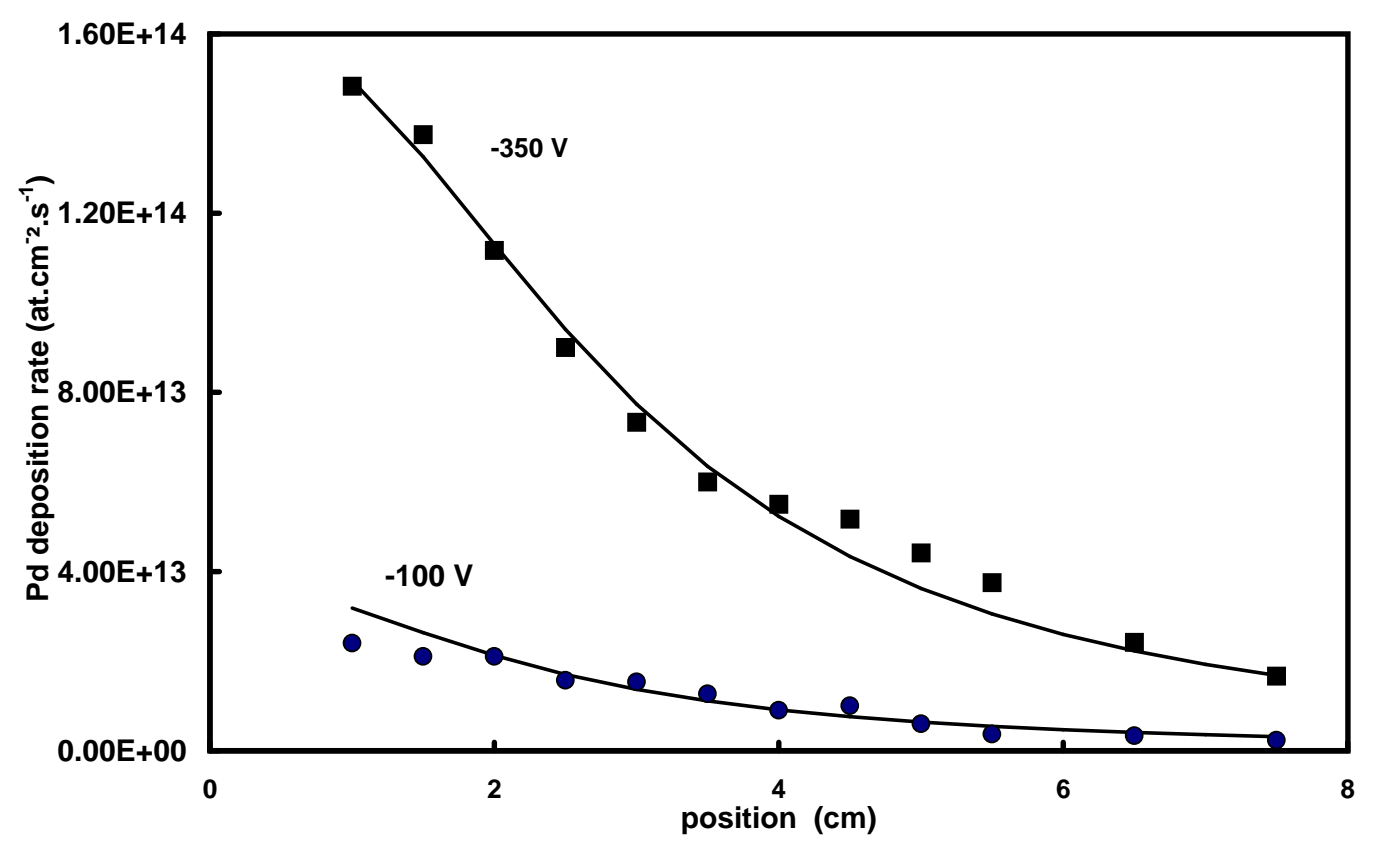

Figure 3. Evolution the $\mathrm{Pd}$ growth rate onto $\mathrm{SiO}_{2} / \mathrm{Si}(100)$ along the diffusion path between $\mathrm{Pd}$ source $(\mathrm{x}=0 \mathrm{~cm})$ and and the reactor wall. Pressure is $100 \mathrm{mTorr}$ and $\mathrm{Pd}$ target wire bias potential is $V_{b}=-100 \mathrm{~V}$ (full circle) and $V_{b}=-350 \mathrm{~V}$ (full square). The lines are the best fits for the diffusion laws (see Table 2)

Table 3. Pd condensation coefficients $\mathrm{S}$ on various subtrates as deduced from deposited quantities $\mathrm{Q}$ and calculated condensation coefficient of $\mathrm{Pd}$ on $\mathrm{SiO}_{2} / \mathrm{Si}(100)$ at $\mathrm{P}=100 \mathrm{mTorr}, V_{b}=-100 \mathrm{~V}, \mathrm{~T}=300 \mathrm{~K}$.

\begin{tabular}{lcc}
\hline Substrate & $\begin{array}{c}\mathrm{Q} \\
\left(10^{15} \mathrm{~cm}^{-2}\right)\end{array}$ & $\mathrm{S}$ \\
\hline $\mathrm{a}-\mathrm{SiO}_{2} / \mathrm{Si}(100)$ & 2.4 & 0.4 \\
$\mathrm{a}-\mathrm{Si}_{3} \mathrm{~N}_{4} / \mathrm{Si}(100)$ & 2.4 & 0.4 \\
$\mathrm{a}-\mathrm{C} / \mathrm{Cu}$ & 2.4 & 0.4 \\
$\mathrm{a}-\mathrm{Al}_{2} \mathrm{O}_{3} / \mathrm{Al}$ & 3.7 & 0.6 \\
$\mu \mathrm{c}-\mathrm{SiC}$ & 5.3 & 0.9 \\
graphite $\mathrm{C}(0001)$ & 1.5 & 0.3 \\
\hline
\end{tabular}


vacuum evaporation on amorphous material as $\mathrm{Al}_{2} \mathrm{O}_{3}$ where at $300 \mathrm{~K}$, values between 0.7 and 0.9 are reported [7]. Differences originate from different surfaces : highly perturbed surfaces exhibit larger condensation coefficients than smooth surfaces.

In conclusion, a simple way for evaluating condensation coefficients in a plasma environment is proposed by measuring growth rates and recording emission line of the depositing species. A relation giving the condensation coefficient in the case of plasma sputtering is deduced. Condensation coefficients of $\mathrm{Pd}$ on various subtrates are thus succesfully estimated.

\section{Acknowledgments}

P. Ranson is gratefully acknowledged for critical reading of the manuscript and fruitful dicussions about OES. M. Mikikian, M. Cavarroc, C. Duluard, L. E. Pichon, H. Rabat, A. Caillard are acknowledged for friendly discussions on plasma surfaces interactions.

\section{References}

[1] Cunge G, Chabert P, Booth J P 2001 J. Appl. Phys. 897750 ; Booth J P 1999 Plasma Sources Sci. Technol. 8 249; Sadeghi N, Derouard J and Booth J P 1997 Plasma Processing of Semiconductors, Proc. of the NATO ASI (Kluwer Academic Publishers, Dordrecht)

[2] Brault P, Thomann A L, Andreazza-Vignolle C 1998 Surf. Sci. Lett. 406 L597

[3] Thomann A L, Rozenbaum J P, Brault P, Andreazza-Vignolle C, Andreazza P 2000 Appl. Surf. Sci. 158172

[4] Thomann A L, Charles C, Brault P, Laure C and Boswell R 1998 Plasma Sources Sci. Technol. 7 245

[5] Thomann A L, Charles c, Cherradi N and Brault P 2000 Plasma Sources Sci. Technol. 9176

[6] Grill A Cold Plasma in Material Fabrications. From Fundamentals to Applications (IEEE Press, New York, 1994)

[7] Henry C R 1998 Surf. Sci. Rep. 31231 